\title{
Queixa Escolar: Encaminhamentos e Atuação Profissional em um Município do Interior Paulista
}

School Complaint: Referrals and Professional Activities in a City in the Interior of São Paulo State

Queja Escolar: Referencias y Actividades Profesionales en una Ciudad del Interior del Estado de São Paulo

Cláudia Aparecida Valderramas Gomes \& Jennifer do Nascimento Pedrero

Universidade Estadual Paulista

http://dx.doi.org/10.1590/1982-3703002192013

(cc) BY 
Resumo: As queixas escolares estão entre os principais motivos de encaminhamento de crianças para atendimento especializado. Esta pesquisa teve por objetivos caracterizar o perfil da demanda encaminhada por queixa escolar aos serviços públicos de saúde de um município do interior paulista no período 2010-2011, bem como identificar e analisar a conduta adotada pelos profissionais da Psicologia no atendimento destinado a ela. Unidades Básicas de Saúde e o Centro Integrado de Atenção Psicossocial - CIAPS - foram os locais designados para a coleta dos dados por serem responsáveis pelo atendimento à população infantil. O estudo contemplou análise documental dos registros sobre a demanda encaminhada e entrevista semiestruturada com os psicólogos que trabalham nos respectivos espaços. Os resultados confirmaram o que aponta a literatura na área da Psicologia Escolar com destaque para o encaminhamento de crianças do sexo masculino com idades entre sete e dez anos que cursam o início do primeiro ciclo do ensino fundamental. Com relação às concepções e práticas profissionais, constatou-se o predomínio do modelo clínico de atenção e certa dificuldade na efetivação de novas formas de atuar. Apesar dos avanços teórico-metodológicos propostos em novas concepções sobre as queixas escolares, estes ainda não se fazem suficientemente presentes na prática desses profissionais.

Palavras-chave: Psicologia. Saúde Pública. Dificuldades Escolares. Atuação do Psicólogo.

Abstract: The complents school 's are among the main reasons for referral of children to specialized care. This study aimed to characterize the profile of the school complaints forwarded by the public health services in a city of country São Paulo state in 2010-2011, and to identify and analyze the conduct adopted by practitioners of psychology in attendance for the same demand. Basic Health Units and Integrated Psychosocial Care Center - CIAPS - were the places designated for data collection to be responsible for meeting the child population. The study included documentary analysis records on semi - structured interviews with psychologists working in the spaces referred demand and interview. The results confirmed the literature indicates that the field of school psychology with emphasis on routing male children between seven and ten years old who attend the beginning of the first cycle of elementary school. About the respect to the concepts and professional practices found a predominance of the clinical model and a certain difficulty to implement new ways of working. Despite the theoretical and methodological advances in proposed new conceptions about school problems, they still aren't sufficiently present in the practice of these professionals.

Keywords: Psychology. Public Health. School Difficulties. Psychologist Performance.

Resumen: Las quejas escolares están entre los principales motivos para orientación de niños en la atención especializada. El presente estudio tuvo por objetivos caracterizar el perfil de la demanda remitida por queja escolar a los servicios de salud pública de un municipio del interior paulista en el periodo 2010-2011, así como identificar y analizar la conducta de los profesionales de psicología en la asistencia a esta demanda. Unidades Básicas de Salud y el Centro Integrado de atención Psicosocial (Ciaps) fueron los lugares designados de colecta de datos pues son responsables por la atención de la población infantil. El estudio contempló el análisis documental de los registros de la demanda y entrevistas semiestructuradas con los psicólogos que trabajan en los respectivos espacios. Los resultados confirmaron lo que apunta la literatura en el campo de la psicología escolar, con énfasis en la orientación de niños del sexo masculino de edades comprendidas entre siete y diez años que cursan al primer ciclo de la educación básica. Con respecto a los conceptos y a las prácticas profesionales se constató el predominio del modelo clínico de atención y algunas dificultades en hacer efectivas nuevas formas de actuar. A pesar de los avances teóricos y metodológicos propuestos en nuevas concepciones sobre las quejas escolares, los mismos todavía no se hacen suficientemente presentes en la práctica de eses profesionales.

Palabras clave: Psicología. Salud Publica. Dificultades Escolares. Actuación del Psicologo. 


\section{Introdução}

Dificuldades de aprendizagem e/ou problemas de comportamento relacionados à escola são denominadas queixas escolares e estão entre os principais motivos de encaminhamento de crianças para atendimento nos sistemas públicos de saúde. Trabalhos produzidos durante a última década, a respeito do atendimento psicológico de crianças na rede pública e em clínicas-escola em diferentes regiões do país, sugerem que uma parcela significativa das queixas apresentadas aos psicólogos nas Unidades Básicas de Saúde se refere à escola. Daí a necessidade de problematizar a maneira como os psicólogos analisam os conhecimentos da área da educação para a compreensão e o atendimento da queixa escolar, bem como identificar os instrumentos e procedimentos teórico-práticos da Psicologia que eles dispõem para acolher e trabalhar com essa demanda.

Como forma de nos aproximarmos dessa realidade educacional, buscamos compreender como acontecia o encontro entre a Psicologia e a Educação, por meio do conhecimento da trajetória dos encaminhamentos de crianças que enfrentavam algum tipo de dificuldade no contexto escolar e do modelo de atendimento profissional dispensado a essa parcela da população, fato que nos levou a propor essa pesquisa.

Partimos da hipótese de que o modelo de atenção dispensado às crianças que chegavam à saúde pública, encaminhadas por dificuldades no seu processo de escolarização, ainda se encontrava ancorado em pressupostos teóricos e práticos advindos de um modelo clínico tradicional da Psicologia, ou seja, que os estudos e pesquisas mais recentes que apontam tendências e avanços na interface da Psicologia com a Educação e oferecem ferramentas teóricas, técnicas e críticas para o atendimento à queixa escolar ainda não se faziam suficientemente presentes na atuação desses profissionais. Assim, o presente estudo tem por objetivos caracterizar o perfil da demanda encaminhada por queixa escolar e compreender o tipo de atendimento oferecido a ela pelos profissionais da Psicologia na área da saúde pública de um município do interior do estado de São Paulo.

\section{Apontamentos sobre a produção do fracasso escolar}

Historicamente as explicações e análises para o fenômeno do fracasso escolar se voltaram para capacidades e processos internos daquele que aprende, desconsiderando o ensino, os mecanismos e funcionamentos escolares que interferem na relação entre o ensinar e o aprender. Baseados no ponto de vista de que a capacidade de aprender e as potencialidades criativas já existiam em cada aluno, esperando para serem despertadas, os psicólogos se tornaram necessários para explicar, diagnosticar e categorizar os casos que não davam certo, atribuindo motivos para o fracasso, não de acordo com o processo (escolar) em que o aluno estava inserido, e sim baseados em deficiências e falhas individuais que tornavam aquele aluno inapto para acompanhar o que a escola oferecia.

Essa individualização do fracasso foi feita com o respaldo de instrumentos psicológicos como os testes de inteligência e de personalidade, elaboração de laudos que serviam como sentenças para a vida escolar daquele aluno e explicações psicologizantes que justificavam cientificamente tal situação, apresentando motivos que iam desde falhas neurológicas até traços de caráter e de personalidade ou uma conturbada dinâmica familiar, isso tudo aliado à pobreza, à miséria, à desnutrição serviam como fatores agravantes e desencadeantes das dificuldades escolares. Tais explicações contribuíram como suporte para que a escola continuasse a ser vista como uma instituição que oferecia as melhores oportunidades culpabilizando alunos, individualmente, por não aproveitá-las.

Contudo, a partir do final da década de 1970 e início dos anos 1980, tem início um processo de ruptura combinado a um movimento de crítica à Psicologia tradicional na explicação do fracasso escolar. O eixo organizador desse movimento são as análises e revisão crítica das relações entre Psicologia e Educação, as 
quais, ao explicitarem os funcionamentos escolares produtores e/ou intensificadores das dificuldades de aprendizagem das crianças, desvelam os mecanismos ideológicos presentes no interior da escola que atribui especialmente às crianças pobres e provenientes da rede pública de educação a culpa pela não-aprendizagem, evasão e fracasso, apresentando a escola como vítima de uma clientela inadequada e despreparada.

Essa versão de que o fracasso escolar é produto da escola e a adoção de um referencial teórico crítico para a análise do processo de escolarização aponta para a complexidade desse processo, tratado até muito recentemente como uma questão individual, familiar ou ainda como uma relação entre professores e alunos. Portanto, a discussão crítica no campo da Psicologia insere um novo eixo de análise: o processo de escolarização e, ao considerá-lo, a Psicologia Escolar passa a enfatizar a necessidade de que a escola seja vista como um espaço em que relações sociais e individuais se articulam numa trama ainda mais complexa e que precisa ser analisada como tal. Mais do que isso, explicitará o fato de que o profissional, muitas vezes, desconhece o que se passa na escola, não tendo a dimensão de que o fracasso ou o sucesso nos processos de ensino e de aprendizagem escolar é muito menos determinado por questões individuais do que por mecanismos institucionais e políticos. No entanto, ainda persiste uma questão: como os profissionais da Psicologia têm recebido e atendido as demandas que advém da escola, denominadas queixas escolares?

\section{O lugar da queixa escolar na interface Psicologia-Educação}

A presença de intercorrências nos processos de aprendizagem escolar de crianças e adolescentes associadas, ou não, a problemas de comportamento tem sido designada queixas escolares, ocupando lugar de destaque nos encaminhamentos. Autores que desenvolvem seus trabalhos na interface com a Psicologia e a Educação (Collares \& Moysés, 1996; Eidt eTuleski, 2010; Guarido,
2010; Meira, 2012; Moysés, 2001; Moysés e Collares, 2010; Souza, 2010) destacam que o aumento expressivo do número de crianças encaminhadas para atendimento especializado evidencia um processo cada vez mais frequente na atualidade que transfere para o plano individual e/ou familiar demandas que se originam na esfera pública e institucional.

Estudos do final da década de 1990 (Collares e Moysés, 1996, Moysés \& Collares, 1997; Patto, 1997) denunciavam a presença dos testes e laudos psicológicos que, a partir dos encaminhamentos de escolares para diagnóstico, buscavam justificar cientificamente a desigualdade, a exclusão e a marginalidade social como expressão de deficiências biopsicológicas e a adesão a uma visão medicalizada do processo de escolarização das crianças.

Os psicólogos vêm se constituindo, no Brasil, em profissionais que recebem os encaminhamentos de crianças com problemas escolares. Alguns trabalhos produzidos durante a última década têm mostrado que a maior parte da demanda encaminhada traz queixas relativas ao processo de escolarização (Braga \& Morais, 2007; Cabral \& Sawaya, 2001; Louzada, 2003; Marçal \& Silva, 2006; Nakamura, Lima, Tada \& Junqueira, 2008; Scortegagna \& Levandowski, 2004; Silva e Romaro, 2010; Souza, 2005; Vanni \& Maggi, 2005).

Tais estudos revelam que mais de $70 \%$ das queixas apresentadas aos psicólogos nas Unidades Básicas de Saúde - UBSs - abarcam questões relacionadas à escola, de ordem pedagógica e/ou comportamental. Esse quadro mostra ainda que, apesar do crescente número de pesquisas nas áreas da Psicologia e da Educação que reafirmam a importância de identificar questões que extrapolam a dinâmica individual e familiar das crianças encaminhadas, persiste uma tendência, tanto por parte dos profissionais da educação quanto da saúde, de tratar os problemas escolares como de origem exclusivamente biológica ou psicológica.

A consulta a alguns trabalhos que versam sobre os atendimentos na área da Psicologia nos 
sistemas públicos de saúde e clínicas-escola em diferentes regiões do país, Uberlândia-MG (Marçal e Silva, 2006), Caxias do Sul-RS (Scortegagna \& Levandowsky, 2004; Vanni \& Maggi, 2005), Espírito Santo (Louzada, 2003), Ribeirão Preto-SP (Cabral e Sawaya, 2001), Porto Velho-RO (Nakamura et al., 2008) e região norte do município de São Paulo-SP (Braga \& Morais, 2007), permitiu a identificação de aspectos comuns entre eles. Estes estudos sugerem que grande parte dos encaminhamentos de crianças e adolescentes para a saúde ocorre por apresentarem queixas escolares e que, portanto, a atuação dos psicólogos, nos serviços públicos de saúde parece estar voltada, predominantemente, para a resolução de problemas enfrentados na área da educação.

Pelo fato de muitos profissionais ainda compreenderem a queixa escolar como um problema individual pertencente à criança encaminhada, eles conduzem o trabalho, essencialmente, por meio da psicoterapia e/ ou orientação familiar, independentemente da análise do contexto institucional em que tais problemas foram produzidos. Prevalece a concepção de que existem, principalmente, questões emocionais ou desordens familiares motivando a queixa.

Outro aspecto destacado por alguns estudos (Braga e Morais, 2007, 2008; Machado, 2004; Souza, 2005) refere-se ao fato de os encaminhamentos serem realizados, na maioria dos casos, por escolas públicas, ou seja, são estas instituições as principais fontes de condução das crianças para atendimento psicológico. Tais resultados indicam que os profissionais da educação realizam encaminhamentos para saúde por compreenderem como distúrbios os problemas de ajustamento escolar construídos, também, a partir da implantação de políticas públicas e outros funcionamentos institucionais (Souza, 2007). Atribuem explicações de ordem biológica a fenômenos sociais, desconsiderando os fatores educacionais, culturais e econômicos envolvidos no processo de escolarização e que influenciam na produção das dificuldades escolares. Na maioria dos estudos, os resultados confirmam o despreparo dos profissionais para o acolhimento da queixa escolar explicitando uma lacuna nos cursos de formação de psicólogos.

\section{Método}

A pesquisa aconteceu em um município localizado a 433 quilômetros da capital do estado de São Paulo. No projeto inicial, optou-se por coletar os dados nas sete Unidades Básicas de Saúde localizadas em diferentes setores da cidade e no Centro Integrado de Atenção Psicossocial - CIAPS - por serem responsáveis pelo atendimento à população infantil. A decisão de estender a pesquisa para este centro se justificou pelo fato deste contar com uma equipe multiprofissional que inclui a presença do psicólogo e atender a demanda infantil encaminhada, dentre outras queixas, por dificuldades de aprendizagem.

O estudo contemplou duas etapas: análise documental dos registros sobre a demanda encaminhada - prontuários e/ou fichas de encaminhamento - e entrevista semidirigida com os psicólogos que trabalhavam nas Unidades Básicas de Saúde e no Centro Integrado de Atenção Psicossocial.

A pesquisa previa a coleta dos dados somente nos equipamentos de saúde em que o atendimento à demanda infantil tivesse acontecido no período 2010-2011. O percurso metodológico determinou a exclusão de algumas UBSs por não ofertarem mais atendimento à população infantil, por dificuldades de acesso aos prontuários e registros dessa demanda e pela recusa de uma profissional em participar do estudo.

Assim, a coleta dos dados por meio da análise documental ocorreu, apenas, no Centro Integrado de Atenção Psicossocial, equipamento social responsável pelo atendimento de crianças encaminhadas por diferentes setores do município onde foi possível acessar os registros dentro do período estipulado para a pesquisa. A exploração das fontes documentais pretendeu buscar dados de caracterização da população, como: sexo, faixa etária 
predominante, segmento e ano de ensino (Educação Infantil, $1^{\circ}$ ou $2^{\circ}$ Ciclo do Ensino Fundamental), bairro onde residem, escola que frequentam, as principais dificuldades enfrentadas, o motivo do encaminhamento, o agente encaminhador, a descrição detaIhada da queixa e outras informações que fossem relevantes para identificação do perfil da demanda.

Com relação à segunda parte da pesquisa, que previa entrevistas com os profissionais da Psicologia, decidiu-se pela sua realização mesmo entre aqueles profissionais que atualmente não atendem mais demanda infantil, mas que o fizeram até os anos de 2008-2009, e com os demais que ainda realizam esse atendimento, totalizando uma amostra de quatro psicólogos.

Vale destacar que nossa decisão de manter a amostra mesmo entre aqueles que atualmente não atendem mais encaminhamento infantil reside no fato de eles terem tido, durante certo período de tempo, contato com a população de crianças que chegavam às unidades com queixa escolar. Os demais psicólogos da saúde foram contatados para verificação sobre sua disponibilidade em participar da pesquisa, desde que tivessem histórico de experiência profissional com essa demanda e ficou constatado que a amostra selecionada era a mais representativa desse perfil.

Nas entrevistas individuais, o instrumento utilizado foi um roteiro contendo questões-chave para caracterização do público por sexo, local de trabalho, tempo de formação e de atuação profissional, cursos de pós-graduação, atividades profissionais realizadas concomitantemente à principal e experiência profissional em instituições escolares.

Outros itens presentes no roteiro buscaram caracterizar e compreender os motivos do encaminhamento das crianças, as causas atribuídas por esses profissionais às dificuldades escolares que se subdividem em problemas de aprendizagem e de comportamento e os modos como entendem a participação da escola e da família na constituição da queixa escolar. Também buscamos saber como realizam sua atividade, no que tange aos instrumentos e práticas utilizadas para a avaliação e para o atendimento às queixas escolares, bem como a maneira como avaliam os resultados de seu trabalho.

As entrevistas foram previamente agendadas e realizadas individualmente, gravadas e transcritas na íntegra, o que permitiu a análise quantitativa e qualitativa das respostas dos integrantes. Os dados referentes às entrevistas foram coletados pela docente-pesquisadora responsável pelo estudo.

Os participantes foram informados sobre os propósitos do estudo e foi assegurado o sigilo da identidade e os cuidados éticos indispensáveis a realização do mesmo. O projeto foi submetido ao Comitê de Ética em Pesquisa com seres humanos da UNESP, tendo sido aprovado (CAAE n ${ }^{\circ}$ 05153812.8.0000.5401; Parecer $\left.n^{\circ} 73994 / 2012\right)$.

\section{Resultados}

Foram avaliados os registros em prontuários referentes ao período 2010-2011 de crianças e adolescentes com idades entre dois e dezesseis anos encaminhadas por queixa escolar, totalizando 52 sujeitos. Analisaram-se as seguintes variáveis: idade, sexo, segmento de ensino, origem do encaminhamento e tipo de queixa.

\section{Achados e considerações sobre os encaminhamentos}

Constatou-se que, nessa amostra, $80 \%$ era do sexo masculino e a faixa etária predominante vai dos sete aos dez anos (57\%), com queixas relacionadas tanto a dificuldades de aprendizagem como a problemas de comportamento. Achados de outras pesquisas apontam para a mesma direção, Braga e Morais (2007) indicam que das crianças atendidas no serviço de saúde mental das UBSs pesquisadas, $70,2 \%$ era do sexo masculino, tinha entre oito e dez anos de idade (média de 9,2 anos) e apresentava queixas escolares $(76,9 \%)$, 
vinculadas a dificuldades de aprendizagem e a problemas de comportamento na escola. Silva (1994) verificou que $59 \%$ do total dos casos atendidos em serviços públicos de saúde mental no município de Ribeirão Preto-SP eram de crianças na faixa etária de sete a doze anos, sendo 43,5\% do sexo masculino. Santos (1990 citado por Souza, 2004), na caracterização da clientela de uma clínica psicológica da prefeitura de São Paulo, constatou que $67,7 \%$ das crianças atendidas eram do sexo masculino. Nakamura et al. (2008) analisaram a demanda encaminhada por queixa escolar no Serviço de Psicologia Aplicada da Universidade Federal de Rondônia em Porto Velho e encontraram dados convergentes, ou seja, a maioria dos encaminhamentos refere-se ao sexo masculino $(77 \%)$, estão entre a faixa etária de 5 a 9 anos (48\%), são estudantes da escola pública $(91 \%)$ e cursam a $1^{\text {a }}$ série do ensino fundamental (22\%).

Souza (2002), analisando os encaminhamentos a uma clínica-escola da cidade de São Paulo, concluiu que a média de idade predominante era de 9,3 anos e que aproximadamente sete em cada dez crianças encaminhadas para a clínica eram meninos. O mesmo estudo indicou ainda que $66 \%$ das crianças estavam entre a $1^{\text {a }}$ e a $3^{\text {a }}$ séries, com $35 \%$ das crianças atendidas na $2^{a}$ série. Bueno et al. (2001 citado por Braga e Morais, 2007), em pesquisa realizada em Unidades Básicas de Saúde da região sul do município de São Paulo, verificaram que $65 \%$ dos casos de crianças atendidas na faixa etária entre sete e doze anos tinham alguma queixa relacionada à escola. Desse total, $27,9 \%$ dos clientes estavam com idade entre nove e dez anos e a maioria cursava a $2^{a}$ série, além disso, mais de $50 \%$ dos casos encaminhados nessa faixa etária eram de meninos (63\%).

Há outros estudos (Cabral \& Sawaia, 2001; Marçal \& Silva, 2006; Nakamura et al., 2008; Santos \& Alonso, 2004; Scortegagna \& Levandowski, 2004) confirmando o fato de os meninos serem os mais encaminhados. De acordo com Souza (2002), existe uma diferença quanto ao motivo do encaminhamento quando comparamos meninos e meninas. Os encaminhamentos por "atitudes consideradas indesejáveis" estão mais presentes na amostra masculina do que na feminina numa frequência de $18 \%$ contra $20 \%$, já os meninos são menos encaminhados por dificuldades no processo de aprendizagem. Reitera que um dos motivos para o maior encaminhamento do sexo masculino tem relação com a diferença de perfis comportamentais entre meninos e meninas e com o tipo de conduta exigida pela escola, a qual parece se antecipar na indicação de acompanhamento profissional no caso da manifestação de comportamentos indesejáveis visando assegurar um padrão de obediência evitando, assim, o risco da delinquência.

As pesquisas anteriormente citadas (Nakamura et al., 2008; Santos \& Alonso, 2004; Scortegagna \& Levandowski, 2004; Souza, 2004) assinalam o fato de que grande parte das crianças atendidas na saúde pública frequentava as séries iniciais do ensino fundamental. Morais e Souza (2001 citados por Braga e Morais, 2007) concluíram em seu estudo que havia um número significativo de crianças da $2^{\text {a }}$ série encaminhadas para atendimento, pois essa série, à época da pesquisa, coincidia com o final do ciclo básico, que era de dois anos ( $1^{\mathrm{a}}$ e $2^{\mathrm{a}}$ séries). Em nosso estudo a incidência maior de encaminhamentos acontece no primeiro ciclo do ensino fundamental e o segundo ano aparece como indicativo do maior número de crianças encaminhadas $(21,56 \%)$.

Quanto à origem dos encaminhamentos, nossos resultados mostraram que a escola é o agente que mais encaminha para os serviços de saúde (50\%) e o professor é o principal informante $(50 \%)$, confirmando outros estudos, tais como os de Marçal e Silva (2006), Braga e Morais, (2007) e Cabral e Sawaya (2001). Santos e Alonso (2004) também referem a escola $(33,64 \%)$ e a família $(32,73 \%)$ como as principais fontes de encaminhamentos. É importante dizer que em nosso estudo há uma lacuna de informações de $28 \%$ que impede a precisão acerca da origem do encaminhamento. 
Nesse equipamento de saúde analisado, a escola permanece liderando a lista das instâncias que mais conduzem crianças para a área da saúde. Isto pode ser explicado tendo em vista aquilo que vem sendo apontado pela literatura desde a década de 1980, e que os estudos mais críticos da Psicologia Escolar já se propunham denunciar, ou seja, a tendência em se alocar no sujeito as dificuldades - de caráter biológico, psicológico ou social - responsáveis pelo seu não-aprender-na-escola, minimizando a participação das relações sociais, políticas, econômicas e institucionais na produção da queixa escolar. Ainda é bastante forte o predomínio de uma visão unilateral que individualiza os processos dificultadores do sucesso escolar, principalmente das crianças provenientes das camadas mais empobrecidas da população, via de regra, usuárias dos serviços de saúde pública para onde costumam ser encaminhadas.

Vale ressaltar que atualmente convivemos com mecanismos eficientes empregados para dissimular os processos de produção do fracasso e exclusão educacional justificando que tanto as dificuldades de aprendizagens como os transtornos de comportamentos podem ser explicados por meio de disfunções neurológicas. Portanto, as tentativas de lidar com casos de fracasso escolar como se eles fossem uma patologia são exemplos de medicalização, ou seja, um recurso utilizado para transformar questões de origem eminentemente social e política em demandas médicas (Collares \& Moysés, 1996).

Quando aplicado à compreensão do comportamento humano, conduz a uma visão individualizada e biologizante, convertendo questões sociais em biológicas. $\mathrm{Na}$ educação escolar, se caracteriza por uma tendência a conceber o não-aprender ou não-se-comportar-na-escola como consequências de transtornos de aprendizagem e/ou de comportamento.

Em relação às demandas escolares presentes neste estudo, encontramos queixas relativas à aprendizagem (26,23\%), descritas como: aprendizagem, memória, leitura e escrita, matemática, falta de atenção, falta de concentração, repetência e não acompanhamento do ritmo da sala. Também foram identificadas queixas que descrevemos por meio do adjetivo comportamento afetivosocial $(59,02 \%)$, tais como: dificuldades de comunicação/participação, nervosismo, ansiedade, insegurança, imaturidade, sem limites, insubordinação, agressividade, timidez/apatia, agitação, medo, autoestima, recusa em fazer atividades. Houve uma terceira categoria - designada outros $(14,76 \%)$ - que incluiu dificuldades na fala, dificuldades motoras, distúrbios alimentares, drogas e maus-tratos.

Para Scortegagna e Levandowski (2004), as queixas múltiplas são mais comuns nos encaminhamentos do que a queixa única. Neste estudo, o total de queixas não correspondeu ao número total de protocolos, representando mais que o dobro dos encaminhamentos. Em seu estudo, Braga e Morais (2007) referem que a maior parte das queixas por problemas de comportamento relacionados à escola foi por agressividade/nervosismo (35,5\%) e dificuldade de socialização (17,8\%).

Os motivos de encaminhamento por problemas de comportamento superaram aqueles por problemas de aprendizagem, o que indica que pode haver, por parte da escola que encaminha, um conjunto de regras e atitudes esperadas que seriam as únicas consideradas adequadas pela mesma (Tabelas 1 e 2).

Modelos de atuação profissional: achados e considerações sobre as entrevistas

O perfil dos participantes mostra que ele é constituído, na sua totalidade, por profissionais do sexo feminino, com idades entre 42 e 50 anos, com um tempo de formação profissional compreendido entre 19 e 24 anos. Também é importante destacar que todas possuem pós-graduação, metade com especializações na área da Psicologia Clínica e a outra com pós-graduação stricto sensu (um mestrado em Psicologia e um em Psicologia Social pela USP).

Quanto à experiência, todas apresentaram mais de dezoito anos de atuação profissional na saúde pública municipal. Das entrevistadas, 
Tabela 1. Descrição dos motivos do encaminhamento ligados à aprendizagem.

\begin{tabular}{lcc}
\hline Motivos/Aprendizagem & $\mathbf{N}^{*}$ & $\mathbf{\%}^{* *}$ \\
\hline Aprendizagem & 7 & 21,8 \\
Memória & 1 & 3,1 \\
Leitura e escrita & 8 & 25 \\
Matemática & 3 & 9,4 \\
Falta de atenção & 5 & 15,6 \\
Falta de concentração & 3 & 9,4 \\
Repetência & 2 & 6,3 \\
Não acompanha o ritmo da sala & 3 & 9,4 \\
\hline Total & 32 & 100 \\
\hline
\end{tabular}

*Número de vezes que aparece o motivo do encaminhamento ligado à aprendizagem.

**Porcentagem sobre o total de cada motivo.

Fonte: Gomes \& Pedrero (2015).

Tabela 2. Descrição dos motivos do encaminhamento ligados ao comportamento.

\begin{tabular}{lcc}
\hline Motivos/Comportamento & $\mathbf{N}^{*}$ & $\mathbf{\%}^{* *}$ \\
\hline Dificuldades de comunicação/participação & 7 & 9,8 \\
Nervosismo & 10 & 14 \\
Ansiedade & 6 & 8,3 \\
Insegurança & 4 & 5,5 \\
Imaturidade & 3 & 4,2 \\
Sem limites & 5 & 6,9 \\
Insubordinação & 5 & 6,9 \\
Agressividade & 9 & 12,5 \\
Timidez/Apatia & 6 & 8,3 \\
Agitação & 8 & 11,1 \\
Medo & 3 & 4,2 \\
Autoestima & 1 & 1,4 \\
Recusa em fazer atividades & 5 & 6,9 \\
\hline Total & 72 & 100 \\
\hline
\end{tabular}

*Número de vezes que aparece o motivo do encaminhamento ligado ao comportamento.

**Porcentagem sobre o total de cada motivo.

Fonte: Gomes \& Pedrero (2015).

duas exercem, concomitantemente, atividade profissional em consultório particular desde que se formaram e outras duas tiveram uma breve experiência profissional no âmbito da rede pública estadual de educação, como professoras de Psicologia no ensino médio. Uma profissional também mencionou sua experiência como psicóloga na secretaria de educação municipal acompanhando os casos designados de queixa escolar.
No item que remete às explicações sobre o que seja uma dificuldade de aprendizagem no contexto escolar, a maioria das respostas foi explanada por: dificuldades de memorização, dificuldades de concentração, dificuldades de atenção, hiperatividade, decorrentes da relação professor-aluno, decorrentes de fatores neurológicos, dificuldades de aprender, questão emocional, questões familiares. Apenas uma profissional mostrou certo cuidado 
na análise e interpretação do que seja uma dificuldade de aprendizagem:

Eu não tenho, procuro não ter uma visão pré-estabelecida, eu procuro contextualizar a partir da realidade de cada criança, você corre o risco de ter uma visão unilateral e perder a verdadeira dimensão de cada queixa, eu procuro não ter uma prévia avaliação, concepção sobre a dificuldade de aprendizagem. Aqui, na minha prática, cada caso que a gente recebe decorre de uma dada realidade, e essa condição individual do caso que me faz trabalhar de um determinado jeito; eu não vou definir uma concepção única porque a questão da aprendizagem pode estar ligada a questões familiares, à própria falência do processo de ensino-aprendizagem; não dá para você previamente definir que aquela questão de aprendizagem está ligada a esse aspecto ou àquele aspecto. Tem que olhar o caso de maneira bastante ampla para poder avaliar e definir, ter um diagnóstico de quais fatores estão interferindo na aprendizagem daquela criança.

Quando solicitadas a responder sobre o que vem a ser um problema de comportamento, grande parte das respostas versou sobre: crianças agressivas, crianças com medo, criança que xinga em sala de aula, que não obedece, que faz bagunça, que sai da sala sem autorização, crianças mais agitadas, com comportamento antissocial, hiperatividade - TDH, falta de limites, falar demais na sala de aula, ou que demonstram desrespeito para com os colegas e professores, ou ainda quando está fora daquele contexto, daquele padrão esperado dentro da escola. Uma psicóloga vinculou os chamados problemas de comportamento a uma dificuldade da escola relativa à motivação:

Eu tenho uma tendência a olhar para o problema de comportamento como uma dificuldade de motivação, eu acho que a maioria das crianças que apresentam problemas de comportamento. A escola, às vezes, se distancia muito das necessidades da criança e esse distanciamento faz com que as crianças não vejam sentido naquilo que está sendo transmitido, e isso faz com que surjam os problemas de comportamento.

Neves e Marinho-Araujo (2006, p.162) discutem a questão das dificuldades de aprendizagem enfatizando que não se pode ter um olhar unilateral acerca de qualquer tipo de comportamento, e acrescentam que só tem sentido falar da dificuldade de aprendizagem quando "[...] plenamente integrada ao processo histórico de cada indivíduo e às múltiplas interações sociais que ocorre no contexto em que ele se insere".

Conforme a Tabela 3, as causas centradas na família se destacam porque aparecem tanto em relação à dinâmica familiar (25\%), quanto relacionadas ao contexto social da criança, remetendo a fala do profissional àquilo que a mesma vivencia na sua relação com a família (25\%).

Quando interrogados sobre a participação da escola na produção da queixa, todos apontam

Tabela 3. Frequência e porcentagem das causas atribuídas pelos psicólogos às queixas escolares.

\begin{tabular}{llc}
\hline Causas das queixas escolares & $\mathbf{N}^{*}$ & $\mathbf{\%}^{* *}$ \\
\hline Dinâmica familiar & 02 & 25 \\
Modo de atuar dos professores & 01 & 12,5 \\
Fator emocional da criança & 01 & 12,5 \\
Escola e sistema educacional & 02 & 25 \\
Contexto social que se relaciona às questões familiares & 02 & 25 \\
\hline Total & 08 & 100 \\
\hline
\end{tabular}

*Número de vezes que cada causa é apontada pelos psicólogos.

**Porcentagem sobre o total de cada causa mencionada pelos psicólogos.

Fonte: Gomes \& Pedrero (2015). 
a mesma como desprovida de instrumentos teóricos e práticos para lidar com a criança que apresenta alguma dificuldade em aprender, mencionando a questão da formação e valorização do professor e os reflexos disso na sua prática pedagógica, na relação que o mesmo estabelece com as necessidades dos alunos. Apesar de identificarem dificuldades da escola em lidar com as diferentes formas de aprender e de se comportar das crianças e apontarem o excesso de encaminhamentos como alguma coisa que poderia ser evitado, não chegam a formular uma análise mais abrangente e crítica das relações, concepções e práticas institucionais que estão na origem de muitos casos de encaminhamentos para a área da saúde.

[...] acho que a formação do professor tem que estar voltada a esse aluno, entendeu? [...] porque eu sou uma professora, eu tenho que acreditar no meu potencial, eu vejo assim, eu sempre achei que você tem que acreditar no seu potencial, e você ser a professora e ensinar, professor não é aquele que todo mundo só tira nota $A$, não é, professor é aquele que sabe entender um ao outro, entender o que está acontecendo, às vezes, aquele aluno não está conseguindo aprender, mas o que será que está acontecendo? [...] Eu vejo a criança que às vezes está com dificuldade e a professora fica com medo, aí eu não consigo dar conta disso, aí, quando chega aqui, chega um caso instalado, uma coisa complicada, que poderia ser resolvida antes, de uma outra forma mas é isso que falta, falta profissionais na educação [...] são pequenas coisas que eu acho que tem que ser antes do encaminhamento.É assim, a gente pensa que a escola talvez não esteja preparada pra esse aluno, porque a gente sabe que a escola tem um padrão pronto pro aluno que se adapta, pro aluno que vai, presta atenção, que está dentro das normas. A escola, me parece, que ela não tem uma coisa mais individualizada [...] é que me parece assim, que esse aluno ele não é olhado de um jeito diferente, vamos ajudar esse aluno a pensar, vamos ver o que vem dele, fazê-lo participar, eu acho que os professores de certa maneira eles são desmotivados. Eu penso que a questão é muito mais profunda, primeiro a insatisfação do professor, primeiro a formação do professor e antes disso ainda, a escolha que o professor faz de fazer Pedagogia, por quê? O que leva ele a fazer Pedagogia? Depois a forma como ele recebe em termos de reconhecimento salarial [...] e tem a coisa do compromisso sabe... se você está com um aluno na sala de aula, a dificuldade que aparece na sala de aula, é minha responsabilidade! Então eu vou reconhecer, o que eu vou fazer com o aluno que está desatento, com o aluno que não tem interesse, sabe... Eu preciso conhecer, eu preciso me aproximar mais, eu preciso conversar, colocar pra fazer atividade na lousa porque assim ele vai se sentir mais valorizado, mais perto de mim, sabe, eu vou ouvir o que está acontecendo com ele, tem uma dificuldade? Será que dá pra fazer uma tarefa com ele que corresponda ao que ele vai poder fazer ou eu tenho que enquadrar, aquilo que está no padrão, sabe? São essas questões, assim, que eu penso que a escola podia repensar, aliás, pensar no aluno antes de encaminhar. A escola tem dificuldades em lidar com aquele aluno que foge às regras estabelecidas pela escola: a regra é ir lá, se comportar e aprender tudo o que é passado, não dar trabalho; se a criança tem alguma necessidade que foge a essas regras previamente determinadas, eu acho que a escola falha no momento de diagnosticar isso e propor atividades que ajudem a criança a superar esse momento de dificuldade, o problema da escola é não conseguir lidar com aquele que foge à regra, que foge à normalidade e aí se torna um problema, é aí, é quando a criança é encaminhada, é sugerido para um atendimento psicológico, mesmo no atendimento pedagógico, acho que decorre de uma dificuldade da escola em lidar com as diferenças, sempre que não segue o padrão - no próprio momento escolar - é porque alguma coisa está errada e aí não é o processo pedagógico que não está dando conta das necessidades das crianças, é a criança que tem alguma dificuldade.

Quanto aos modos como esses profissionais realizam seu trabalho no atendimento às queixas escolares, o presente estudo subdividiu as questões entre avaliação e atendimento propriamente dito. As Tabelas 4 e 5 demonstram os modelos de atenção mais encontrados. 
Tabela 4. Frequência e porcentagem das práticas de avaliação realizadas pelos psicólogos.

\begin{tabular}{llc}
\hline Atividades realizadas pelos psicólogos & $\mathbf{N}^{*}$ & $\mathbf{\%}^{* *}$ \\
\hline Hora lúdica & 04 & 21,05 \\
Entrevista inicial & 02 & 10,53 \\
Entrevista de anamnese & 03 & 15,79 \\
Testes & 02 & 10,53 \\
Contato com a escola pessoalmente & 02 & 10,53 \\
Contato com a escola (telefone e/ou questionário) & 03 & 15,79 \\
Atendimento grupal com a criança & 01 & 5,26 \\
Observação da criança & 01 & 5,26 \\
Devolutiva & 01 & 5,26 \\
\hline Total & 19 & 100 \\
\hline
\end{tabular}

*Número de vezes que cada atividade é apontada pelos psicólogos.

**Porcentagem sobre o total de cada atividade mencionada pelos psicólogos.

Fonte: Gomes \& Pedrero (2015).

O questionário referido pelos profissionais diz respeito a um instrumento elaborado, em parceria, pelas secretarias da educação e da saúde para ajudar na explicação de cada caso. Ele é preenchido pela escola-coordenadores pedagógicos e professores - informando sobre a criança encaminhada, porém, segundo os entrevistados, se constitui apenas como mais um recurso na análise e compreensão da queixa.

[...] é que os encaminhamentos vêm pela escola, então quem informa é a professora, eu não tomo aquele questionário como tudo Aquele questionário, pra mim, é só pra eu entender o que está acontecendo, o que eu vejo como questão, o que eu vejo na criança, meu olhar é pra criança e pra família, aquilo lá ajuda um pouco pra entender como ta a situação na escola.

Com relação à conduta adotada pelos psicólogos na área da saúde, o trabalho de Bueno et al. (2001 apud Braga \& Moraes, 2007) aponta o predomínio da orientação familiar, o psicodiagnóstico e as terapias individuais e em grupo. Braga e Morais (2007) também referem que a orientação familiar foi a conduta que mais se destacou no conjunto analisado e, nos casos de queixa escolar, a prática mais freqüente foi a terapia individual.
Em consonância com outros estudos que buscaram analisar concepções e práticas de psicólogos alocados em serviços públicos de saúde (Cabral \& Sawaya, 2001), observamos, nesta pesquisa, uma prevalência do atendimento clínico individual (30\%), sobre a orientação familiar (20\%) e escolar (10\%).

Apenas uma profissional menciona o fato de quase não ficar com a criança em atendimento individual, apontando um modelo de trabalho que inclui ir até a escola, acompanhar o trabalho pedagógico em sala de aula, fazer contatos com a professora e promover um intercâmbio dessas observações com aspectos identificados na interlocução com as famílias.

Na maioria, é orientação familiar ou
orientação na escola, são poucos os casos
que eu fico com a criança... Eu trabalho
orientação com os pais, com a família e
trabalho com orientação na escola, visita
escolar, eu observo a sala de aula, né... A
partir da observação da sala de aula, eu
faço contato com a professora, às vezes,
dou orientação para o professor, volto
com a família, faço essas coisas...

Em resposta à questão sobre como os profissionais avaliam os resultados do trabalho da Psicologia no atendimento às queixas escolares, todos referiram dificuldades e falhas no processo vinculando-as 
Tabela 5. Frequência e porcentagem das práticas de atendimento realizadas pelos psicólogos.

\begin{tabular}{lll}
\hline Atividades realizadas pelos psicólogos & $\mathbf{N}^{*}$ & \%** $^{* *}$ \\
\hline Orientação familiar & 02 & 20 \\
Orientação escolar & 01 & 10 \\
Observação na sala de aula & 01 & 10 \\
Atendimento grupal no serviço de saúde & 01 & 10 \\
Atendimento individual (psicoterapia lúdica) & 03 & 30 \\
Encaminhamento para outras áreas & 02 & 20 \\
\hline Total & 10 & 100 \\
\hline
\end{tabular}

* Número de vezes que cada atividade é apontada pelos psicólogos.

**Porcentagem sobre o total de cada atividade mencionada pelos psicólogos.

Fonte: Gomes \& Pedrero (2015).

à estrutura organizacional do trabalho na saúde pública - que inclui carência de recursos físicos, materiais e humanos -, ao distanciamento com a escola e também em relação ao modelo de trabalho que ainda privilegia a conduta clínica individual.

Há um teor de insatisfação presente nas falas das profissionais com relação aos resultados do trabalho de atenção à queixa escolar, evidenciado, principalmente, pela elevada expectativa que se construiu acerca do trabalho do psicólogo na solução independente dos problemas advindos da escola. Elas demonstram sentir necessidade de um trabalho coletivo, de uma (re) aproximação com profissionais da educação recuperando momentos da história do município em que isso acontecia; queixam-se do distanciamento e argumentam a necessidade de inovar construindo outros modelos de atenção que viabilize parcerias, desde o trabalho com as crianças em grupos e oficinas até a interlocução e discussão de casos com outros profissionais.

Contudo, ainda se faz presente na maioria das respostas a concepção de que possíveis dificuldades que originam problemas escolares estão centradas nas crianças ou em suas famílias, sejam elas vinculadas a problemas com a autoestima ou ao envolvimento e participação familiar no processo educacional e terapêutico.

Quando questionadas sobre o seu processo de formação profissional, se o mesmo ofereceu condições suficientes para desenvolver um trabalho junto à demanda de queixa escolar, todas referiram a insuficiência dos estudos na graduação, argumentando que os cursos posteriores (especializações e mestrados) e a prática profissional foram contribuindo para ampliar a capacidade de entendimento acerca dessa problemática. Contudo, fica evidente que isso pouco contribuiu para alterar substancialmente o olhar clínico.

Eu tenho pouca formação, por exemplo, em trabalho pedagógico, por exemplo, na minha época lá de formação. Eu acho que a Psicologia mudou muito nessa questão de Psicologia escolar, porque, na minha época, eu lembro que foi passado pra gente mais ou menos uma visão do psicólogo que tá na escola, ele tá pra atender a criança-problema, como se fosse uma clínica dentro da escola.Eu tive uma formação, na minha época, era a psicanálise puramente. [...] Então, eu acho que o que me fez pensar e atuar de forma diferente foram os espaços que eu fui ocupando posteriormente. Eu acho que também tem uma coisa da gente ter, parece, uma tendência já em se posicionar de uma forma e não de outra, né? Eu me envolvia, na formação, com ações mais sociais, com grupos, com o CCl, eu fiz estágio lá, então já era uma vertente de olhar diferente, né, mas não acho que foi fundamental, foi isso que me levou... Estudos na pós, a prática, envolvimento com os movimentos sociais...

Pois é, a minha formação.... eu sei lidar muito com a questão afetiva da criança 
[...] Agora eu acabo trabalhando as questões afetivas e emocionais de comportamento e de relação que estão interferindo na questão escolar, que estão dificultando, agora essa parte da psicopedagogia, talvez seja interessante trabalhar...

Cabral e Sawaya (2001, p. 152) referem que "embora a literatura aponte o quanto a psicologia vem nas últimas décadas questionando sua atuação profissional, buscando outros caminhos para o entendimento dos problemas escolares das crianças", isso ainda não se faz presente nas práticas dos psicólogos.

Em relação à formação profissional e a entrada do psicólogo para o campo da assistência pública à saúde, em especial nas UBSs, Dimenstein (1998) discute algumas situações que contribuíram, a partir dos anos 1980, para a ocupação dos espaços públicos pelos psicólogos: a mudança nas políticas públicas na área da saúde, a limitação do mercado dos atendimentos em consultórios privados em razão da crise econômica, a ampliação dos cursos de formação de psicólogos e a consequente dificuldade de absorção desses profissionais que se formavam a cada ano, além da difusão da psicanálise.

No conjunto de participantes desse estudo, todas concluíram sua formação inicial no período de 1988 a 1993 e ingressaram na saúde pública municipal na primeira metade da década de 1990. Esses elementos de alguma forma refletem os achados da literatura, ou seja, são profissionais que passaram por uma formação que privilegiava o referencial teórico da psicanálise com um forte assento na prática clínica individual e passaram a ocupar um espaço profissional na área da saúde reproduzindo na esfera pública o modelo hegemônico de atuação clínica do psicólogo aprendido nos cursos de formação.

\section{Considerações finais}

A literatura tem ressaltado a importância de conhecer as características e peculiaridades de determinada clientela como forma de subsidiar as intervenções. Em resumo, podemos dizer que o presente estudo apresenta pontos coincidentes com os achados da literatura na área da Psicologia Escolar, principalmente no que tange à caracterização da demanda encaminhada por queixa escolar aos serviços de saúde pública e aos modelos de atendimento dispensado às crianças que chegam a tais serviços.

A resposta à pergunta sobre quem são as crianças encaminhadas se aproxima de resultados obtidos em outras pesquisas de diferentes regiões do estado de São Paulo e mesmo do Brasil, dado que denota a necessidade de pensarmos em alguns desdobramentos. $\mathrm{O}$ primeiro deles diz respeito ao modo como as escolas realizam o processo de encaminhamento: é preciso pensar nos aspectos que são (des) considerados ao se fazer a indicação da necessidade de um especialista para solucionar questões de origem escolar. A naturalização desse processo e o fluxo contínuo de produção de demandas para a área da saúde podem sinalizar uma transferência de responsabilidades de uma área a outra como forma de simplificar problemas oriundos de um contexto, certamente, repleto de questões a serem reavaliadas e ressignificadas.

Outro diz respeito à questão das políticas públicas educacionais que precisam ser problematizadas ${ }^{1}$. Trata-se de refletir a produção da queixa do interior de uma escola que ainda é excludente, que não oferece a todos as mesmas oportunidades, nem tampouco os mesmos recursos de acesso e apropriação efetiva do conhecimento. Estamos diante de uma escola pública atravessada por um conjunto de dispositivos legais, medidas, projetos e programas governamentais que traduzem a legitimação da ordem capitalista sob a bandeira da defesa dos direitos sociais.

Aos educadores que vislumbram o atendimento às crianças na área da saúde como forma de sanar sintomas, vale ponderar que os mecanismos produtores e/ou intensificadores das queixas de aprendizagem e de comportamento podem permanecer invisíveis enquanto não se fizer uma análise crítica dos processos políticos e ideológicos que perpassam as 
relações institucionais escolares, fato que requer questionar, dentre outros aspectos, o papel das políticas públicas educacionais que vem se constituindo ao longo do tempo em ferramentas mantenedoras do processo de produção da exclusão educacional no que concerne à qualidade do ensino.

Ainda persiste, na visão de alguns profissionais, a ideia de que as queixas escolares que chegam aos diferentes setores de atendimento à demanda infantil referem-se, tão somente, a casos individualizados considerados, pela escola, como problemáticos e difíceis de lidar, que escapam ao seu controle e desafiam formas instituídas de permanência em seu interior. Pouco se discute sobre os efeitos das políticas públicas dirigidas à área da educação que tem afetado professores, gestores, familiares e estudantes de maneira geral.

A eficácia desse ensino e a dinâmica institucional que conforma a produção das queixas escolares e encaminhamentos nem chegam a ser questionadas porque sucumbem a uma análise superficial da situação das crianças e de suas famílias, especialmente aquelas provenientes das camadas mais empobrecidas da população usuária de uma escola precarizada e refém de um ensino de má qualidade.

O fato de a escola aparecer como protagonista dos encaminhamentos aos setores da saúde, conforme referido em diferentes estudos, nos coloca o desafio de pensar a atuação profissional do psicólogo que, ao atender esses encaminhamentos, precisa ponderar a produção dessa queixa e buscar respostas condizentes com um modelo de atuação institucional, ofertando um conhecimento teórico-prático que contribua para aproximar crianças, adolescentes e o conhecimento escolar garantindo, efetivamente, seu direito à aprendizagem e ao desenvolvimento.

O modelo de atenção profissional dispensado às queixas escolares na área da saúde pública municipal, e identificado nessa pesquisa, também confirma a maioria dos achados na literatura, quando se trata da interface entre Psicologia-Educação, ou seja, predomina uma vertente teórica e prática de base psicanalítica que transparece em atendimento clínico individual com a criança ou de orientação à família.

Outra dificuldade identificada nesse estudo que confirma estudos anteriores (Braga \& Morais, 2007; Dimenstein, 1998) é a dificuldade de a Psicologia trabalhar intersetorialmente, ou seja, sabe-se que uma parcela dos problemas que se apresentam na saúde pública, dentre eles a questão da queixa escolar, não pode ser resolvida isoladamente, já que são demandas interligadas com questões institucionais, políticas e econômicas (Braga \& Morais, 2007).

Essa questão nos coloca, novamente, frente à necessidade de repensar os processos de formação profissional do psicólogo no que tange ao enfrentamento das queixas escolares. A Psicologia construiu ao longo dos últimos vinte e cinco anos um referencial teórico e prático que lhe permite uma análise crítica acerca da produção de demandas advindas da educação, evidenciando um conjunto de elaborações que precisam ser considerados quando se trata de formar psicólogos. 
Asbahr, F. S. F., Viégas, L. S., \& Angelucci, C. B.(2006). Políticas públicas em educação \& psicologia escolar. São Paulo, SP: Casa do Psicólogo.

Braga S. G., Morais, M. L. S. (2007). Queixa escolar: atuação do psicólogo e interfaces coma educação. Psicologia USP, 18(4), 35-51.

Braga S. G., Morais, M. L. S. (2008). Saúde mental em Unidades Básicas de Saúde: o caso da queixa escolar. Boletim do Instituto de Saúde, (45), 34-36.

Cabral, E., Sawaya, S. M. (2001). Concepções e atuação profissional diante das queixas escolares: os psicólogos nos serviços públicos de saúde. Estudos de Psicologia, 6(2), 143-155.

Collares, C. A. L. \& Moysés, M. A. A. (1996). Preconceitos no cotidiano escolar: ensino e medicalização. São Paulo, SP: Cortez.

Dimenstein, M. D. B. (1998). O psicólogo nas Unidades Básicas de Saúde: desafios para a formação e atuação profissionais. Estudos de Psicologia, 3(1), 53-81.

Eidt, N. M. \& Tuleski, S. C. (2010). Transtorno de déficit de atenção/ hiperatividade e psicologia histórico-cultural. Cadernos de Pesquisa, 40(139), 121-146.

Gomes, C. A. V.; \& Pedrero, J. N. (2015).

Guarido, R. (2010). A biologização da vida e algumas implicações do discurso médico sobre a educação. In: Conselho Regional de Psicologia de São Paulo, Grupo Interinstitucional Queixa Escolar (Orgs.), Medicalização de crianças e adolescentes: conflitos silenciados pela redução de questões sociais a doença de indivíduos (pp.27-39). São Paulo, SP: Casa do Psicólogo.

Louzada, R.C.R. (2003). Caracterização da clientela atendida no Núcleo de Psicologia Aplicada da Universidade Federal do Espírito Santo. Estudos de Psicologia, 8(3), 451-457.

Machado, A. M. (2004). Relato de uma intervenção na escola pública. In Machado, A.M., \& Souza, M. P. R. (Orgs.), Psicologia escolar: em busca de novos rumos (pp. 143-158). São Paulo, SP: Casa do Psicólogo.
Marçal, V. P. B., \& Silva, S. M. C. (2006). A queixa escolar nos ambulatórios públicos de saúde mental: práticas e concepções. Revista Semestral da Associação Brasileira de Psicologia Escolar e Educacional (ABRAPEE), 10(1), 121-131.

Meira, M. E. M. (2012). Para uma crítica da medicalização na educação. Revista Semestral da Associação Brasileira de Psicologia Escolar e Educacional, 16(1), 135-142.

Moysés, M. A. A. (2001). A institucionalização invisível: crianças que não aprendem na escola. São Paulo, SP: Companhia de Letras.

Moysés, M. A. A., \& Collares, C. A. L. (2010). Dislexia e TDAH: uma análise a partir da ciência médica. In Conselho Regional de Psicologia de São Paulo; Grupo Interinstitucional Queixa Escolar (Orgs.), Medicalização de crianças e adolescente: conflitos silenciados pela redução de questões sociais a doença de indivíduos (pp. 71-110). São Paulo, SP: Casa do Psicólogo.

Moysés, M. A. A., \& Collares, C. A. L. (1997). Inteligência abstraída, crianças silenciadas: as avaliações de inteligência. Psicologia USP, 8(1), 63-89.

Nakamura, M. S., Lima, V. A. A., Tada, I. N. C., Junqueira, M. H. R. (2008). Desvendando a queixa escolar: um estudo no Serviço de Psicologia da Universidade Federal de Rondônia. Revista da Associação Brasileira de Psicologia Escolar e Educacional, 12(2), 423-429.

Neves, M. M. B. J., \& Marinho-Araujo, C. M. (2006). A questão das dificuldades de aprendizagem e o atendimento psicológico às queixas escolares. Aletheia, 24, 161-170.

Patto, M. H. S.(1997). Para uma crítica da razão psicométrica. Psicologia USP, 8(1), 47-62.

Santos, W. P., \& Alonso, M. Z. (2004). Caracterização da demanda infantil de um serviço de psicologia. Revista Ministério da Saúde Pública, 3(5), 35-42.

Scortegagna, P., \& Levandowski, D.C. (2004). Análise dos encaminhamentos de crianças com queixa escolar da rede Municipal de Ensino de Caxias do Sul. Interações, 9(18), 127-152. 
Silva, R. C. (1994). O fracasso escolar: a quem atribuir? Paidéia, (7), 33-41.

Silva, R.V.S., Romaro, R.A. (2010). Caracterização das queixas de mau desempenho escolar. Psicopedagogia On Line. Recuperado de: www.psicopedagogia.com.br

Souza, B. P. (Org.) (2007). Orientação à queixa escolar. São Paulo, SP: Casa do Psicólogo.

Souza, M. P. R. (2004). As contribuições dos estudos etnográficos na compreensão do fracasso escolar no Brasil. In Machado, A. M. \& Souza, M. P. R. (Orgs.), Psicologia escolar: em busca de novos rumos (pp. ). São Paulo, SP: Casa do Psicólogo.

Souza, M.P.R.(2002). Problemasdeaprendizagem ou problemas de escolarização? Repensando o cotidiano escolar à luz da perspectiva histórico-crítica em psicologia. In Oliveira, M. K., Souza, D. T. R., \& Rego, T. C. (Orgs.),
Psicologia, educação e as temáticas da vida contemporânea (pp. 177-195). São Paulo, SP: Moderna.

Souza, M. P. R. (2005). Prontuários revelando os bastidores do atendimento psicológico à queixa escolar. Estilos da Clínica, 10(18), 82-107.

Souza, M. P. R. (2010). Retornando à patologia para justificar a não aprendizagem escolar: a medicalização e o diagnóstico de transtornos de aprendizagem em tempos de neoliberalismo. In Conselho Regional de Psicologia de São Paulo; Grupo Interinstitucional Queixa Escolar (Orgs.), Medicalização de crianças e adolescentes: conflitos silenciados pela redução de questões sociais a doenças de indivíduos. (pp. 57-67). São Paulo, SP: Cada do Psicólogo.

Vanni, M. G., \&Maggi, A. (2005). O que demanda à psicologia na rede pública de saúde em Caxias do Sul? Psico, 36(3), 299-309. 


\section{Cláudia Aparecida Valderramas Gomes}

Doutora em Educação pela Faculdade de Filosofia e Ciências da Universidade Estadual Paulista-UNESP, Marília-SP. Brasil. Docente do Departamento de Psicologia Evolutiva, Social e Escolar e do Programa de Pós-Graduação em Psicologia da Universidade Estadual Paulista - UNESP, Assis - SP. Brasil.

E-mail: claugomes@assis.unesp.br

\section{Jennifer do Nascimento Pedrero}

Discente em Psicologia pela Universidade Estadual Paulista - UNESP - SP. Brasil.

E-mail: jennipedrero@yahoo.com.br

\section{Endereço para envio de correspondência:}

Av. Dom Antonio, 2100. Parque Universitário. Departamento de Psicologia Evolutiva, Social e Escolar da FCL/UNESP. CEP: 19806-900. Assis - SP. Brasil.

Artigo elaborado com base nos resultados de pesquisa que contou com o apoio do Programa Primeiros Projetos - Pró-Reitoria de Pesquisa - PROPe/UNESP (2012-2013). Para uma análise crítica acerca das políticas públicas educacionais, ver Asbahr, Viégas e Angelucci, 2006.

Recebido: 25/11/2013, 1 a Reformulação: 29/09/2014, Aprovado: 14/09/2015. 